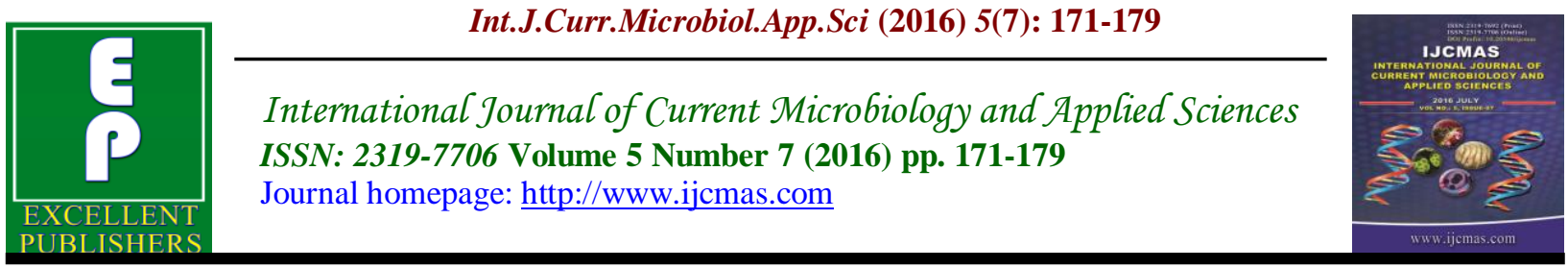

Original Research Article

http://dx.doi.org/10.20546/ijcmas.2016.507.017

\title{
Genetic Diversity Study of Bacteria Associated with Clarias gariepinus from Ebute-Ibooro on Yewa River using Random Amplified Polymorphic DNA
}

\author{
O.O. Oyelakin ${ }^{1}$, J.K. Ekelemu ${ }^{2 *}$, A.A. Akinyemi ${ }^{3}$, A.R. Oloyede ${ }^{1}$ and M.E. Ige ${ }^{3}$ \\ ${ }^{1}$ Biotechnology Centre, Federal University of Agriculture, Abeokuta, Nigeria \\ ${ }^{2}$ Department of Fisheries, Delta State University, Asaba Campus, Delta State, Nigeria \\ ${ }^{3}$ Department of Aquaculture and Fisheries Management, Federal University of Agriculture, \\ Abeokuta, Nigeria \\ *Corresponding author
}

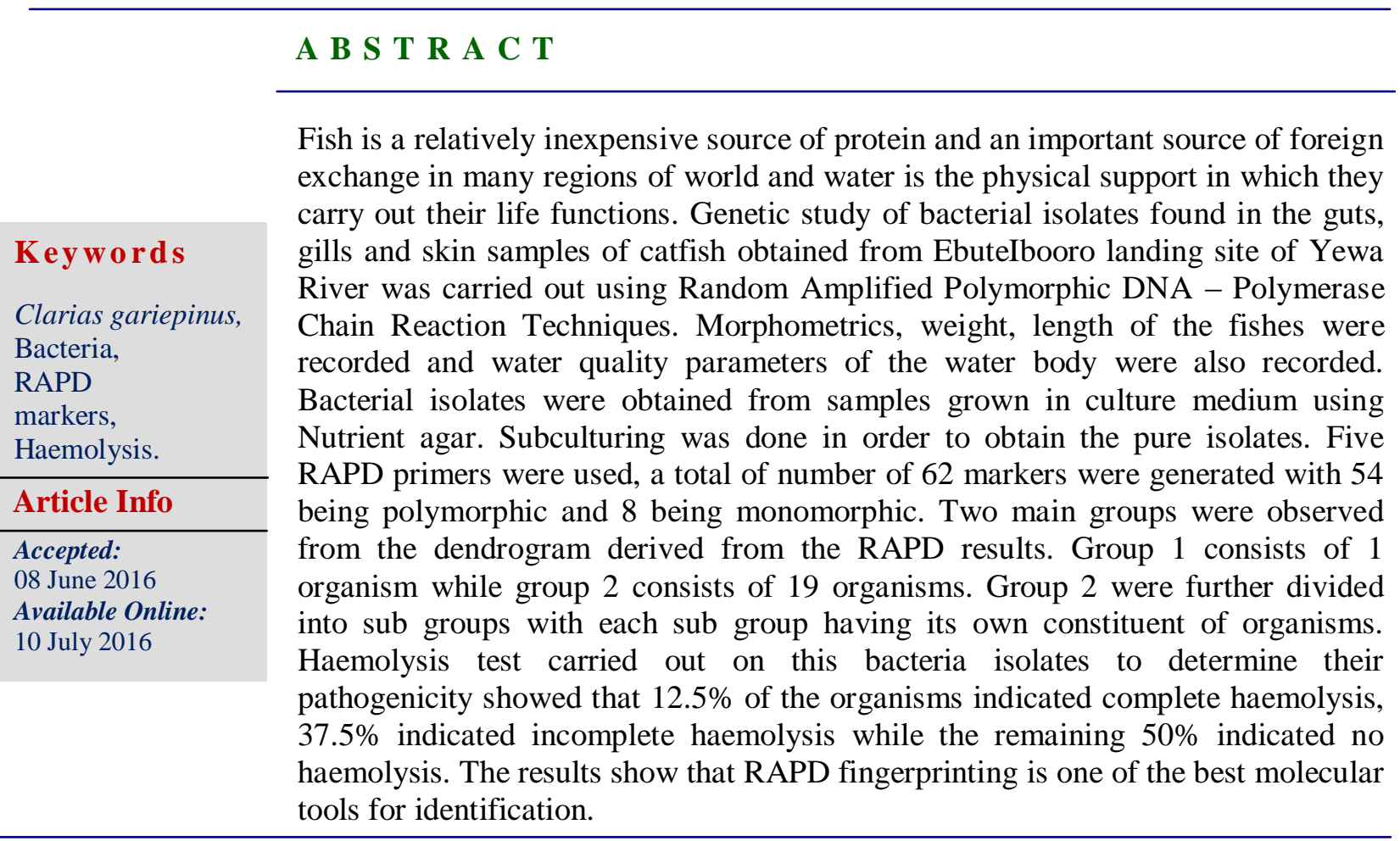

\section{Introduction}

Fish is an inexpensive source of protein and an important cash crop in many regions of world and water is the physical support in which they carry out their life functions such as breathing, excretion of waste, feeding, maintaining salt balance and reproduction, swimming, breeding, digestion and excretion (Bronmark and Hansson, 2005).
Claridae is the name of the family to which most catfishes belong to. This claridae family is also known as "omnivorous scavengers". This categories of fish lack scale and they possesbarbels (feelers). They also have pectoral fin, head, mouth and respiratory origins. These enable the fish to stay for some time outside water, making 
use of atmospheric oxygen (Sydenham, 1975). Catfish is of considerable importance; many of the larger species are farmed and fished for food. Many of the smaller species particularly the genuscrydoras are important in the aquarium hobby (Nelson, 2006).

Aquatic microbes cause infection in fishes. The entry and establishment of pathogenic microbes are facilitated through the injuries caused by parasitic infestation. Fish and Shellfish not only transmit disease to man but are themselves subject to many diseases and capable of transmitting many of the established food borne microbial infections and intoxications (FAO, 1974). Trichodinaand Trichodinella which make up the Trichodina complex, Gyrodactylus spp, Edward siellaictaluri, cysts of Henneguya spp are some of the infectious agent of the clarids.

The use of the RAPD analysis is sufficiently discriminatory for the typing of the E. coli isolates. Characterization of Escherichia coli isolated from cultured catfish by antibiotic resistance and RAPD analysis RAPD-PCR (Samuel, 2011). The number of DNA bands produced for a given primer ranged from 1 to 5 with molecular sizes ranging from 200 bp - 1500 bp. The possible number of RAPD patterns was estimated by the changes of one or more clear bands or band size. There were 9 RAPD patterns (P1-P9) observed using GEN15009 primer. The RAPD-PCR analysis using combination of primers GEN15009 and GEN15010 allowed all the strains of E. coli to be differentiated into 13 different genome types, U1 to U13. This indicates that by using combination of primers, the E. coli strains can be differentiated into more groups compared to when using these primers individually. Sarkar (2012) while studying Characterization of Aeromonas hydrophila through RAPD-PCR and SDS-PAGE Analysis isolated Aeromonas hydrophilia from fish (Labeorohita) in pond water, river water, raw meat of chicken and mutton and raw cow milk were characterized through Random Amplified Polymorphic DNA (RAPD) analysis and Sodium Dodecyl Sulphate Polyacrylamide Gel Electrophoresis (SDS PAGE) of cellular proteins. RAPD-PCR amplification of bacterial DNA was done by using ten random primers (OPA-01 to 10) and found some distinct banding pattern on agarose gel. RAPD profile was studied with each isolate and absolute polymorphism indicating its usefulness as an ideal tool for molecular characterization. Other methods like morphological, serological and biochemical characterization gives contradictory results and total cellular protein profiling does not show any significant polymorphism for identification and discrimination.

Molecular characterization of Enterotoxigenic Bacillus cereus species isolated from tropical marine fishes using RAPD markers by Prasad (2014) selected some tropical fishes which were shark, anchovy, ribbion fish, sole, mackerel, seer, tuna, snapper, sardine, and pomfret commercially available in Bangalore region. The bacteria were isolated on to marine agar. All the strains were morphologically and biochemically characterized to be Bacillus cereus. A total of 10 primers of the OP series were used in the present study. RAPD PCR using primers OPB-08 and OPD-20 generated maximum banding pattern in this study showed high polymorphism between selected Bacillus cereus species. Visualizing the physical appearance of hemolysis in cultured blood samples may be used as a tool to determine the species of various Gram-positive bacteria infections. Haemolysis is the 
breaking down of the red blood cells. It is one of the major aspects of determining the pathogenicity of an organism. Pathogenicity is the ability of an organism to invade and destroy human cells, tissues and metabolism.

\section{Materials and Methods}

\section{Sample Collection}

Bacteria samples were collected from gills, gut and skins of Catfish Clarias gariepinus in Ebute Ibooro landing site of Yewa River with the aid of swab sticks. 16 adult catfish were collected from the river and swab sticks were used to obtain samples from the fish. Morphological characteristics of the fish such as the head length, total length and standard length were determined. The weight of an individual fish was also determined and the water quality features of the area such as dissolved oxygen, temperature and $\mathrm{pH}$ were taken in situ.

\section{DNA extraction and RAPD-PCR}

Bacteria isolates grown overnight were transferred to eppendorf tube and it was spun down at 14,000 rpm for 2 mins. DNA was extracted using the CTAB method Akinyemi and Oyelakin (2014). The quality and integrity of the DNA was fractionalized on $1.0 \%$ agarose gels. The reaction mix was carried out in $20 \mu \mathrm{l}$ final volume containing 60ng - 80ng genomic DNA, $0.1 \mu \mathrm{M}$ of the primers, $2 \mathrm{mM} \mathrm{MgCl} 2,125 \mu \mathrm{M}$ of each dNTP and 1 unit of Taq DNA polymerase. The thermocycler profiles has an initial denaturation temperature of 3 mins at $94^{\circ} \mathrm{C}$, followed by 45 cycles of denaturation temperature at $94^{\circ} \mathrm{C}$ for 20seconds, annealing at $37^{\circ} \mathrm{C}$ for 40 seconds and primer extension at $72^{\circ} \mathrm{C}$ for 40 seconds, followed by final extension temperature at $72^{\circ} \mathrm{C}$ for 5 mins was added. PCR amplicon electrophoresis was carried out by size fractionation on $2.0 \%$ agarose gels.

\section{Statistical Analysis}

The bands obtained from the gel was transferred to numerical figure, 1 represents presence of a band while 0 is absence of a band, it was later subjected to analysis using NTSYS software to draw the dendogram for the bacteria isolates.

\section{Haemolysis}

$10 \mathrm{~g}$ of Nutrient agar was weighed and dissolved in $100 \mathrm{ml}$ of distilled water and mixed thoroughly. The mixture was autoclaved for sterilization at $121^{\circ} \mathrm{C}$ for 15 minutes. The Nutrient medium was then brought out to cool to the point that it could not burn the skin. Human blood was added

\section{Results and Discussion}

Table 1 showed the various standard lengths, total lengths and head lengths with their weights inclusive. The mean total length, mean standard length, mean head length, mean weight of the fish was determined to be $47.00 \pm 12.00(\mathrm{~cm})$, $41.25 \pm 6.50(\mathrm{~cm}), \quad 10.47 \pm 2.00(\mathrm{~cm})$, $785.50 \pm 713.00(\mathrm{~cm})$ respectively. Figure 2 showed the electrophoresis gel for RAPD primer OPH 08. Plate 1 showed the DNA of the bacteria isolates visualized and photographed on UV light source while plate $2 \mathrm{~A}$ and $2 \mathrm{~B}$ showed the PCR amplification visualized and photographed on UV light source. It can be deduced from Table 2 that there were 54 polymorphic markers generated from the five RAPD markers. There were also 8 monomorphic markers from the primers. A total number of 62 markers were generated. Twelve alleles from the first primer OPB-12, 13 alleles from the second primer OPB-20 and 17 
alleles from the third primer OPH-08. Also, there were 5 alleles from OPH 12 and 7 alleles from OPH 09. Figure 4 showed the dendrogram for the 20 bacteria isolates. At $50 \%$, the organisms showed a lot of similarities but at $56.5 \%$, there was a difference and the organisms were divided into 2 groups with organism 11 standing in group 2 and the other organisms in group 1 . At $69 \%$, the organisms were divided into subgroups with organism 2, 4, 6 and 7 are in a particular group and the rest in another groups. Table 4 showed the result of the ability of the isolated organism to produce Lysins which indicates the pathogenicity of such organisms. $12.5 \%$ of the organisms showed complete haemolysis, $37.5 \%$ showed incomplete haemolysis while the remaining 50\% showed no haemolysis.

The RAPD technique constitutes an efficient tool for the study of the DNA polymorphism. It involves the amplification of random segments of genomic DNA by polymerase chain reaction (PCR) using short single primers of arbitrary sequence. RAPD requires very small quantities of DNA while no cloning, sequencing or hybridization is necessary. For these reasons and with the condition that only a little within-group polymorphism exist, it has a marked advantage over other molecular techniques generally used for genomic studies. Random amplified polymorphic DNA- polymerase chain reaction (RAPD-PCR) was used to discriminate bacteria isolated from fishes in the rivers considering their guts, skins and gills.

There were 54 polymorphic markers generated from the five RAPD markers. 8 monomorphic markers were derived from the primers. A total number of 62 markers were generated. 12 alleles from the first primer OPB-12, 13 alleles from the second primer OPB-20 and 17 alleles from the third primer OPH-08. Also, there were 5 alleles from OPH-12 and 7 alleles from OPH-09. Percentage polymorphisms of primers OPB12, OPB-20, OPH-08, OPH-12 and OPH-09 were 100, 100, 89, 63, and 70 respectively. Polymorphism indicates that the alleles are together and that they are coding for the same thing. At 50\%, the organisms showed a lot of similarities but at $56.5 \%$, there was a difference and the organisms were divided into 2 groups with organism 11 standing in group 2 and the other organisms in group 1 . At $69 \%$, the organisms were divided into subgroups with organism 2,4,6 and 7 are in a particular group and the rest in another groups.

The result above is in agreement with a very similar study by Prasad (2014) in order to determine the molecular characterization of Enterotoxigenic Bacillus cereus species isolated from tropical marine fishes using RAPD markers $85.71 \%$ and $56.25 \%$ polymorphism was observed in OPB-8 and OPD-20 respectively, which indicates high genetic variation among the Bacillus cereus strains isolated from tropical marine fishes. According to dendogram analysis of band pattern generated by Primer OPB-8, Bacillus cereus Strain 4 and 3 were closely related whereas strain 4 and Strain 2 were genetically more diverse. On the other hand, dendogram obtained from OPD-20 Primer RAPD-PCR data showed that Bacillus cereus Strain 2 and Strain 4 were genetically more similar whereas Strain 4 and Strain 1 were least similar to each other.

Samuel (2011), in a study to determine the Characterization of Escherichia coli isolated from cultured catfish by antibiotic resistance and RAPD analysis RAPD-PCR used primers GEN15009 and GEN 15010. The number of DNA bands produced from a given primer ranged from 1 to 5 with molecular sizes ranging from $200 \mathrm{bp}-1500$ 
bp. The possible number of RAPD patterns was estimated by the changes of one or more clear bands or band size. There were 9 RAPD patterns observed using GEN15009 primer. The RAPD-PCR analysis using combination of primers GEN15009 and GEN15010 allowed all the strains of E. coli to be differentiated into 13 different genome types. This indicate that by using combination of primers, the E. coli strains can be differentiated into more groups compared to when using these primers individually. Hence, combined primers provide increased sensitivity towards genetic variations. Some of the E. coli strains have indistinguishable RAPD fingerprinting profiles which suggest that they may be closely related or have no genetic differences. Certain isolates did not produce band in this analysis mainly because there were no sequence in the bacterial DNA which is complementary to the sequence of the primer. The dendograms generated clearly established the genetic relatedness of the E. coli strains, the information that may be useful in epidemiological and population studies.

$12.5 \%$ of the organisms showed complete haemolysis, $37.5 \%$ showed incomplete haemolysis while the remaining $50 \%$ showed no haemolysis. One strain of Aeromonas hydrophila was tested which showed complete haemolysis. There was also one strain of Pantoeaan thophila, Serratia nematodiphila, Shigella boydii, Bacillus spp., Serratia liquefaciens and Morganella morganii which showed incomplete haemolysis. Two strains of Pseudomonas spp. were tested showing complete and no haemolysis. Four strains of
Citrobacter freundii were tested showing $75 \%$ no haemolysis and $25 \%$ incomplete haemolysis. Complete haemolysis shows that they are pathogenic to the fishes and they can also be pathogenic to humans when consumed. There were differences between strains of certain bacteria over the type of haemolysis they exhibit. This concurs with a similar work by Uaboi-Egbenni et al., (2010) while examining the significance of pathogenic bacteria in the gut of swimming crab, Callinecte ssp obtained from Lagos lagoon and market samples stored at freezer temperature $\left(0^{\circ} \mathrm{C}\right)$ conducted a blood haemolysis test which showed that the bacterial species isolated from the gut of the swimming crabs are usually found as pathogens associated with the guts of warmblooded animals

Frazier and Westhoff (1988); Owhe-Ureghe et al. (1993) in their studies have implicated Bacillus cereus and Bacillus subtilis in infections and food poisoning. The pathogenesis of Escherichia coli and its occurrence as faecal contaminant has been reported (Frazier and Westhoff, 1988). Other workers have reported virulence and pathogenic E. coli strains in different animals. In humans (Reid et al., 2000; Kaper, 2004); in avian (Audouin gulls) (Carmada et al., 2007); in poultry (JanBen et al., 2001). Hussein (2006) reported the prevalence and pathogenicity of shiga toxinproducing $E$. coli in beef and their products. Schmid-Hempel and Frank (2007) observed in their study that in E. coli as small as 10 cells are infectious enough to establish disease condition, whereas the dosage can be very high in other pathogens like Vibrio cholera (103-108 cells). 


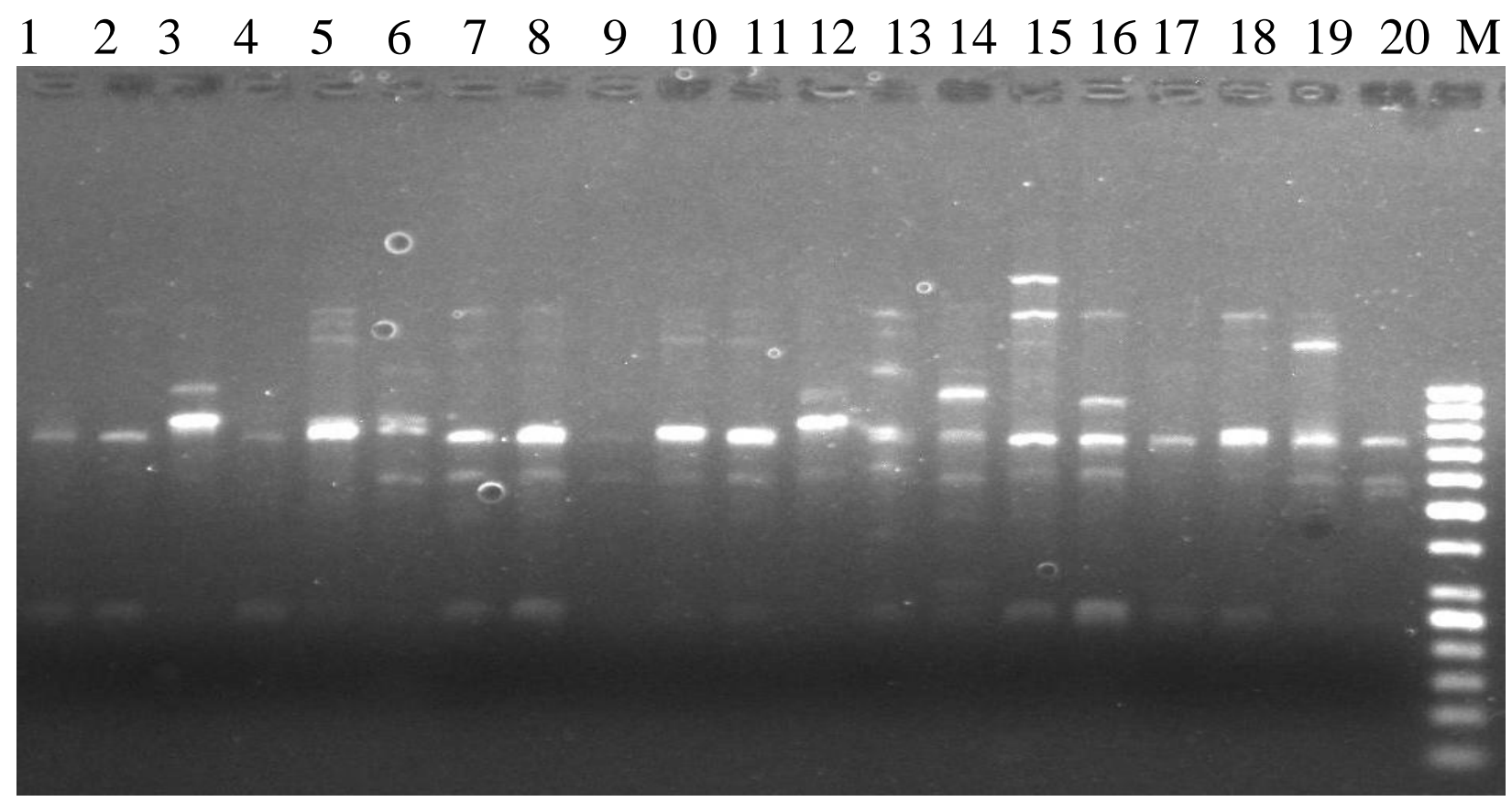

Plate.1 Electrophoresis gel for RAPD primer OPH 08

Table.1 showing the measurement of the morphometric features of the fish

\begin{tabular}{ll}
\hline Parameter & Mean value \pm SE \\
\hline Mean weight & $785.50 \pm 81.20(\mathrm{~g})$ \\
Total length & $47.00 \pm 0.97(\mathrm{~cm})$ \\
Standard Length & $41.25 \pm 0.84(\mathrm{~cm})$ \\
Head length & $10.47 \pm 0.30(\mathrm{~cm})$ \\
\hline
\end{tabular}

Table.2 Primer Sequences and percentage polymorphism

\begin{tabular}{|l|l|l|l|l|l|l|}
\hline S/N & $\begin{array}{l}\text { Primer } \\
\text { name }\end{array}$ & $\begin{array}{l}\text { Primer } \\
\text { Sequences }\end{array}$ & $\begin{array}{l}\text { No of } \\
\text { Monomorphic } \\
\text { markers }\end{array}$ & $\begin{array}{l}\text { No of } \\
\text { Polymorphic } \\
\text { markers }\end{array}$ & $\begin{array}{l}\text { Total no } \\
\text { of } \\
\text { markers }\end{array}$ & $\begin{array}{l}\text { Percentage } \\
\text { Polymorphism }\end{array}$ \\
\hline 1 & OPB 12 & CCTTGACGCA & Nil & 12 & 12 & 100 \\
\hline 2 & OPB 20 & GGACCCTTAC & Nil & 13 & 13 & 100 \\
\hline 3 & OPH 08 & GAAACACCCC & 02 & 17 & 19 & 89 \\
\hline 4 & OPH 12 & ACGCGCATGT & 03 & 05 & 08 & 63 \\
\hline 5 & OPH 19 & CTGACCAGCC & 03 & 07 & 10 & 70 \\
\hline & Total & & 08 & 54 & 62 & \\
\hline
\end{tabular}


Table.3 Results showing the haemolysis of the isolated bacteria

\begin{tabular}{ccc}
\hline Organism & Tissues & Type of Haemolysis \\
\hline Sample 1 & Gill & $\beta$ \\
Sample 2 & Gill & $\alpha$ \\
Sample 3 & Skin & $\alpha$ \\
Sample 4 & Skin & $\gamma$ \\
Sample 5 & Gills & $\alpha$ \\
Sample 6 & Gut & $\alpha$ \\
Sample 7 & Skin & $\beta$ \\
Sample 8 & Gut & $\alpha$ \\
Sample 9 & Skin & $\gamma$ \\
Sample 10 & Skin & $\gamma$ \\
Sample 11 & Gill & $\gamma$ \\
Sample 12 & Skin & $\gamma$ \\
Sample 13 & Gut & $\alpha$ \\
Sample 14 & Skin & $\alpha$ \\
Sample 15 & Gill & $\beta$ \\
Sample 16 & Skin & $\gamma$ \\
Sample 17 & Skin & $\gamma$ \\
Sample 18 & Skin & $\gamma$ \\
Sample 19 & Gut & $\alpha$ \\
Sample 20 & Gill & $\alpha$ \\
\hline
\end{tabular}

KEY: $\alpha$ - Incomplete haemolysis; $\beta$ - Complete haemo;ysis; $\gamma$ - No Haemolysis

Fig.1 Dendrogram for the 20 Bacteria Isolates

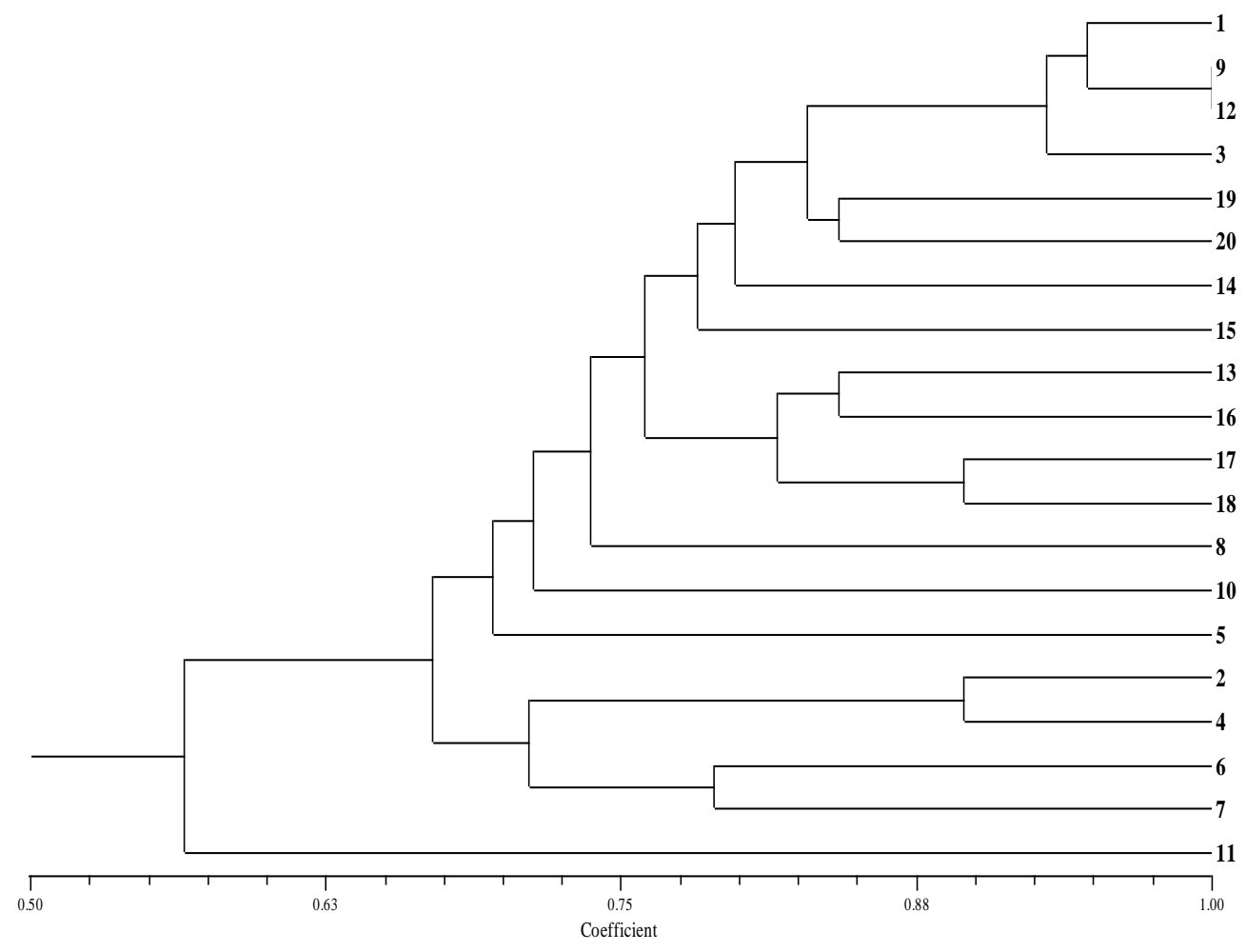


In conclusion, the presence of these organisms were known to be a major cause of infections in human and animals as it signified a potential threat to farmers who tend to source for their seeds in the wild, fishermen and also consumers through potential transfer of resistance to human and animal pathogens. RAPD marker could be used to study the genetic diversity of bacteria associated with fishes in the wild pointed towards the amplicons generated by OPH-08. The species specificity can be confirmed only by checking these primes with isolates of other similar bacteria. This was also evident in the dendogram showing the genetic relationship between these organisms. Large number of RAPD genotypes can be an ideal method for species identification (Hadrys et al., 1992). The results show that RAPD fingerprinting is one of the best molecular tools for identification. Nevertheless, RAPD fingerprinting allows the identification of strains but the high variability limits its potential as an aiding method for species identification.

The discrimination of bacteria species can be done by haemolysis tests using blood agar medium. Other than ultramicroscopic, morphological and molecular studies this experiment also conveys the species differentiation due to its lytic activity. Thus, blood agar medium can be a useful medium for pathogenic bacteria survey and investigation. The present review has proved the importance of blood agar utilization in diagnostics and disease analysis.

\section{References}

Ahmad, G., Mudasir, Kudesia, R., Shikha, Srivastava, M.K. 2010. Evaluation of genetic diversity In pea (Pisumsativum L) using RAPD analysis. Genetic Engi. Biotechnol. J., Volume 2010: GEBJ-16
Brock, T.D. 1986. Introduction: An overview of the thermophiles. In: Brock TD (ed.) Thermophiles:

General, Molecular, and Applied Microbiology. New York: Wiley. $1-16$.

Bronmark, C., Hansson, L.A. 2005. The biology of lakes and ponds, Oxford University Press, Oxford, pp 285.

Carmada, A., Circella, E., Giovanardi, D., Pennelli, D., Battist, P., Campagnari, E., Bruni, G., Tagliabue, S. 2007. Avian pathogenic E. coli in Audouin gulls (Larusaudouinii) could they affect the surviving of the bird colonies. Ital. J. Anim. Sci., 6: 317320.

FAO/WHO. 1974. Food and Agriculture Organization of the United Nations and World.

FDF. 2007. Federal Department of Fisheries. Fisheries Statistics of Nigeria, Fourth

Frazier, W.C., Westhoff, D.C. 1988. Food Microbiology. Tata-McGraw-Hill Publishers Co., New Delhi, pp: 410.

Hadrys, H., Balick, M., Schierwater, B. 1992. "Applications of Random Amplified Polymorphic DNA (RAPD) in Molecular Ecology," Mol. Ecol., Vol. 1, No. 1, pp. 55-63.

Health Organization Technical Report series (No. 550) Fish and Shellfish Hygiene report of WHO expert committee convened in cooperation with FAO.

Hussein, H.S. 2006. Prevalence and pathogenicity of shiga toxin-producing E. coli in beef cattle and their Guerrant, 2007. Prevalence, Haemolytic, products. J. Anim. Sci.

JanBen, T., Schwarz, C., Preikschat, P., Voss, M., Phillis, H.C., Wieler, L.H. 2001. Virulence associated with genes in avian pathogenic $E$. coli (APEC) isolated from internal organs of poultry having died from 
colibacillosis. Int. J. Med. Microbioiol., 291: 371- 378.

Kaper, J.B. 2004. Pathogenic Escherichia coli. Nat. Rev. Microbiol., 2: 123-140.

Miyata, M., Aoki, T., Inglis, V., Yoshida, T., Endo, M. 1995. "RAPD Analysis of Aeromonas salmonicida and Aero-monas hydrophila," J. Appl. Microbiol., Vol. 79, No. 2, pp. 181185.

Mohamed, A.M., Sharaf El-Din, A.T., Mohamed, A.H., Habib, M.R. 2011. Identification`of various Biomphalariaalex and rinastrains collected from five Egyptian governorates using RAPD and species-specific PCR techniques. American J. Mol. Biol., 1: 1725.

Nelson, J.S. 2006. Fishes of the World. John Wiley \& Sons, Inc. ISBN 0471250317.

Ogunbayo, S.A., Ojo, D.K., Popoola, A.R., Sie, M., Sanni, K.A., Nwilene, F.E., Somado, E.A., Guei, R.G., Tia, D.D., Oelakin, O.O., Shitu, A. 2007. Genetic Comparisons ofLandrace Rice Accessions by Morphological and RAPDs Techniques. Asian J. Plant Sci., 6(4): 654-666.

Owhe-Ureghe, U.B., Afe, O., Ekundayo, D.E., Agbolahor, P., Oboh, A., Orhue, P. 1993. Bacteriological examination of some "ready to eat" foods marketed in Ekpoma, Edo State Nigeria. Nig. Fd. J., 11: 45-52.

Prasad, M.P. 2012. Molecular characterization of enterotoxigenic Bacillus cereus species isolated from tropical marine fishes using RAPD markers. Int. J. Pure Appl. Biosci.

Reid, S.D., Herbelin, C.J., Bumbaugh, A.C., Selander, R.K., Whittam, T.S. 2000. Parallel evolution of virulence in Pathogenic E. coli. Nature, 406: 6467.

Samuel, L., Marian, M.M., Apun, K., Lesley, M.B., Son, R. 2011. Characterization of Escherichia coli isolated from cultured catfish by antibiotic resistance and RAPD analysis Int. Food Res. J., 18(3): 971976.

Sarkar, A., Saha, M., Patra, A., Roy, S. 2012. Characterization of Aeromonas hydrophila through RAPD-PCR and SDS-PAGE Analysis. Open J. Medi. Microbiol., 2: 37-40.

Schmid-Hempel, P., Frank, S.A. 2007. Pathogenesis, virulence and infective dose of pathogens. PloSPathog., 3: e147.

Sydenham, D.H.J. 1975. Observation of the fish populations of the Nigeria forest stream. Rev.2001.Afr. vol. LXXXIX, fasc. 2 , pp. $257-272$.

\section{How to cite this article:}

Oyelakin, O.O., J.K. Ekelemu, A.A. Akinyemi, A.R. Oloyede and Ige, M.E. 2016. Genetic Diversity Study of Bacteria Associated with Clarias gariepinus from Ebute-Ibooro on Yewa River using Random Amplified Polymorphic DNA. Int.J.Curr.Microbiol.App.Sci. 5(7): 171179. doi: http://dx.doi.org/10.20546/ijcmas.2016.507.017 